\title{
Transição Ensino Médio - Ensino de Engenharia na perspectiva do Professor de Matemática
}

\section{Transition High School - Engineering Education in the perspective of Mathematics Teacher}

\author{
Elenilton Vieira Godoy ${ }^{a}$; Fabio Gerab ${ }^{b}$ \\ a Departamento de Matemática, Universidade Federal do Paraná, Curitiba, Brasil - elenilton@ufpr.br \\ b Departamento de Matemática, Centro Universitário FEI, São Bernardo do Campo, Brasil - prifgerab@ fei.edu.br
}

\section{Palavras-chave: \\ Educação básica. \\ Educação superior. \\ Ensino de engenharia. \\ Ensino de matemática.}

Resumo: O presente estudo faz parte do projeto "Desafios do ensino de Matemática nos cursos de Engenharia, no século XXI", que busca investigar e propor ações para a melhoria da transição Ensino Médio - Ensino de Engenharia. Foram analisadas as respostas de 27 docentes do Departamento de Matemática de uma tradicional escola de Engenharia do ABC Paulista a um questionário contendo 49 questões. A amostra coletada representou $69 \%$ da população de interesse. A análise dos dados ocorreu por meio do tratamento estatístico e por meio de Análise de Conteúdo. Por meio destas análises foram criados cinco constructos pertinentes ao trabalho docente. Os resultados apontam para uma opinião relativamente homogênea sobre os constructos identificados. As pequenas diferenças entre os grupos de professores parecem estar associadas às concepções pedagógicas de cada docente, sem com isso, indicar um grupo característico de professores. Constata-se forte adesão dos docentes à cultura organizacional da IES. Assim, mudanças de abordagens pedagógicas devem atentar-se às políticas institucionais, pois a visão corporativa na IES e suas tradições sobrepor-se às visões individuais.

\section{Keywords:}

Basic education.

College education.

Engineering teaching.

Mathematics teaching.
Abstract: The present study is part of the project "Challenges of the teaching of Mathematics in the Engineering courses in the XXI" century, whose objective is to investigate and propose actions for the improvement of the transition High School Engineering Teaching. The answers in a questionnaire containing 49 questions, given by 27 professors of the Department of Mathematics of a traditional college of Engineering of $\mathrm{ABC}$ Paulista, were analyzed. The sample collected represented $69 \%$ of the population of interest. The analysis of the data occurred through the statistical treatment and through Content Analysis. These analyses define five constructs pertinent to the teaching work. The results point to a relatively homogeneous opinion about the identified constructs. The small differences between the groups of teachers seem to be more associated to the pedagogical conceptions of each teacher, without indicating a characteristic group of teachers. There is strong adherence of teachers to the college culture. Thus, changes in pedagogical approaches must be attentive to institutional policies, since its corporate vision and its traditions overlaps with individual visions. 


\section{Introdução}

\section{A transição do Ensino Médio para o Ensino Superior}

O presente estudo é parte do projeto intitulado "Desafios do ensino de Matemática, nos cursos de Engenharia, no século XXI", que tem como objetivo investigar e propor ações para a melhoria da transição da Educação Básica para a Educação Superior, mais particularmente, para os cursos de Engenharia e viabilizar o uso de aulas mais operatórias ${ }^{1}$, contextualizadas e aplicadas vislumbrando melhorar a compreensão e entendimento da Matemática dita superior.

Esta parte do projeto refere-se ao estudo de campo realizado junto aos professores do departamento de Matemática de uma Instituição de Ensino Superior privada confessional. A pesquisa foi realizada por meio da aplicação de um questionário contendo quarenta e nove questões, distribuídas em questões métricas, categóricas, abertas e em escalas de Likert. O questionário foi disponibilizado aos docentes na plataforma do "Google Docs" no período compreendido entre os dias 03/03/2015 e 03/04/2015. A amostra coletada foi de 27 questionários respondidos.

A proposta de elaborar e aplicar um questionário aos docentes do departamento de Matemática da IES teve a intenção de diagnosticar se esses professores revisitam (com qual frequência) a sua prática docente, ouvir e relatar as experiências de sucesso e/ou fracasso dos docentes em suas aulas e coletar sugestões de ações que poderiam contribuir para a melhoria da transição do Ensino Médio para o Ensino Superior e acolhimento dos alunos ingressantes e

Como acolher e orientar a aprendizagem dos estudantes que ingressam nos cursos universitários iniciais de matemática, requeridos para estudos nas áreas de engenharia, ciências e matemática, é algo que persiste como um desafio para nós e para diversas universidades pelo mundo. A transição matemática ensino médiosuperior na área técnico-científica tem sido objeto de preocupação internacional e se configura como um desafio para professores e uma barreira para alunos. (PALIS, 2010, p.1)

Para Dias e Mateus (2015, p. 140) as dificuldades associadas à transição da Educação Básica para a Educação Superior, no que diz respeito à Matemática, referem-se "ao choque entre as organizações matemáticas das duas instituições que refletem contradições e mudanças bruscas entre os respectivos contratos didáticos institucionais".

O professor que trabalha na área de Matemática com alunos recém-ingressos no Ensino Superior não tem, em geral, uma percepção clara das aprendizagens anteriores dos alunos e tendem a supervalorizá-las ou subvalorizá-las. Além disso, se detém pouco a analisar a qualidade do conhecimento que o seu aluno está construindo. O professor universitário das disciplinas iniciais de matemática precisa reconstruir uma série de conceitos e de procedimentos cuja construção começou nos Ensinos Fundamental e Médio: por exemplo, os conceitos de número e de função,

\footnotetext{
${ }^{1}$ É essencial estabelecer relações entre o mundo e a disciplina, entre a teoria e a prática. A aula é o espaço para o desenvolvimento e a organização do pensamento, propiciando a construção do espírito crítico, das habilidades de pensamento. $\mathrm{Na}$ aula, não se privilegia a transmissão de conteúdos prontos, acabados, mas se constrói e se sistematiza o conhecimento. Para que isso aconteça, a aula deve ser operatória. (BASEIO; GARCIA, 2010).
} 
objetos básicos de trabalho em cursos de Cálculo. Este professor se pergunta: Com que formas de raciocínio, conceitos e processos matemáticos os meus alunos têm familiaridade? Que posso fazer para criar uma ponte entre o conhecimento já construído por eles e aquele que eu pretendo que construam? (PALIS, 2010, p. 2).

Bass (1998, apud, PALIS, 2010), considera que estudos envolvendo à transição matemática ensino médio-superior, na área técnico-científica, requerem mais atenção por parte dos pesquisadores da área de Educação Matemática. A pouca comunicação existente entre docentes dos dois níveis educacionais é um ponto a ser melhorado.

Harel (2006) confirma essa carência, ao dizer que tal transição não tem sido suficientemente examinada. Professores universitários não compreendem as questões envolvidas nesta transição do ponto de vista dos professores secundários, nem vice-versa. Há necessidade urgente de uma melhor comunicação entre os dois setores educacionais. (HONG et al. 2009; CLARK; LOVRIC, 2008). (PALIS, 2010, p. 2).

É fato que comunicação é um fator importante a ser investigado, contudo, o término da vida escolar (Educação Básica) e o início da vida acadêmica (Educação Superior) também requerem atenção por parte da comunidade de Educação Matemática. Há, para além da transição entre as matemáticas, fatores que influenciam a adaptação acadêmica dos ingressantes.

De acordo com Cunha e Carrilho (2005, p. 216), o estudante experiencia variadas mudanças que, por consequência, produzem problemas associados à adaptação acadêmica "resultado das experiências concomitantemente entre às exigências colocadas pelo contexto e às características desenvolvimentais dos próprios a alunos (...).”

Rickinson e Rutherford (1995; citados por Santos, 2000) argumentam que estas dificuldades influenciam negativamente no rendimento acadêmico, aumentam os índices de evasão e de pedidos aos serviços de apoio psicossocial. (CUNHA; CARRILHO, 2005, p. 216)

Em consonância com Cunha e Carrilho (2005, p. 216), o êxito no processo de adaptação, principalmente no primeiro ano (nos dois primeiros ciclos) no Ensino Superior, “aparece como preditor importante da persistência e do sucesso dos alunos ao longo das suas experiências acadêmicas, bem como determina padrões de desenvolvimento estabelecidos pelos alunos ao longo de sua vida universitária (...)".

O primeiro ano da graduação ao curso superior é considerado um período crítico, pois exige adaptação e integração ao novo ambiente. O modo como é vivenciada esta experiência depende tanto do apoio da universidade como das características individuais de cada um (Almeida, 1998a; Pires, Almeida \& Ferreira, 2000; Almeida, Soares \& Ferreira, 1999; Cochrane, 1991; Pascarella, 1985; Ferreira, Almeida \& Soares, 2001). (CUNHA; CARRILHO, 2005, p. 216)

Consideramos, neste sentido, de extrema relevância, a necessidade de cuidar do estudante. É fato que o cuidado deve ser um ato contínuo, contudo, no início do percurso acadêmico, ele deve ser potencializado, uma vez que se trata de um momento (período) crítico para o desenvolvimento do estudante e para a sua adaptação acadêmica. 
Nesta fase, o estudante experiencia vários desafios provenientes das tarefas psicológicas normativas inerentes a transição da adolescência para a vida adulta que quando confrontadas com as exigências da vida universitária constitui-se um desafio a ser vencido. (...) Sendo assim, mostra-se evidente que o aluno universitário necessita de uma atenção especial para que os desafios encontrados na adaptação ao curso superior estimulem a sua transição da adolescência para a vida adulta e não gerem consequências negativas no nível do aproveitamento acadêmico destes alunos. (CUNHA; CARRILHO, 2005, p. 216)

Ao estabelecermos um olhar atento para o estudante ingressante, oportunizando situações para que o mesmo desenvolva as suas competências intelectuais, acadêmicas e pessoais, nós, professores e IES, contribuiremos para o sucesso acadêmico deles, emergiremos como facilitadores "do desenvolvimento pessoal dos jovens, promovendo a integração e o ajustamento (adaptação) acadêmico, pessoal social e afetivo do aluno (Ferreira, Almeida \& Soares, 2001).” (CUNHA; CARRILHO, 2005, p. 216)

Portanto, consideramos que um docente do Ensino Superior que, frequentemente, revisita a sua prática poderá desenvolver esse olhar mais atento o estudante ingressante, uma vez que a revisitação de sua prática docente deverá, do nosso ponto de vista, contemplar os processos de ensino e de aprendizagem.

Delineado um pouco o nosso cenário de investigação, na sequência, apresentaremos o percurso metodológico do estudo realizado junto aos docentes, bem como as várias ferramentas de análise quantitativas e qualitativas, os resultados obtidos e as considerações finais.

\section{O percurso metodológico do estudo realizado junto aos docentes}

O estudo de campo foi realizado a partir da aplicação de um questionário, com questões abertas e fechadas, aos docentes do departamento de Matemática. Ressalta-se que as questões fechadas foram construídas a partir de escalas de cinco pontos de Likert.

O questionário foi composto de quarenta e nove questões, sendo nove métricas, seis categóricas, treze abertas e vinte e uma em escalas de Likert. A amostra coletada de 27 questionários respondidos representa $69 \%$ da população de interesse. O questionário construído foi dividido em seis partes, conforme os dados descritos no "Quadro 1". 
Quadro 1: A organização do questionário

\begin{tabular}{|l|l|l|}
\hline PARTE & $\mathrm{N}^{\circ}$ & QUESTÕES \\
\hline Caracterização do perfil docente & 1 & 1 a 17 \\
\hline A sua prática docente & 2 & 18 a 33 \\
\hline Atitude docente & 3 & 34 a 38 \\
\hline Objetivos docentes & 4 & 39 a 42 \\
\hline Aprendizagem discente & 5 & 43 a 48 \\
\hline Do real para o ideal & 6 & 49 \\
\hline
\end{tabular}

Fonte: Própria.

\section{A caracterização do perfil docente}

As primeiras dezessete questões foram destinadas à caracterização do perfil docente e, neste sentido, destaca-se que:

a) A idade média dos docentes é de 53,8 anos, com um erro padrão de 2,2 anos, o que indica que há um largo espectro de idades, conforme histograma apresentado na figura 1.

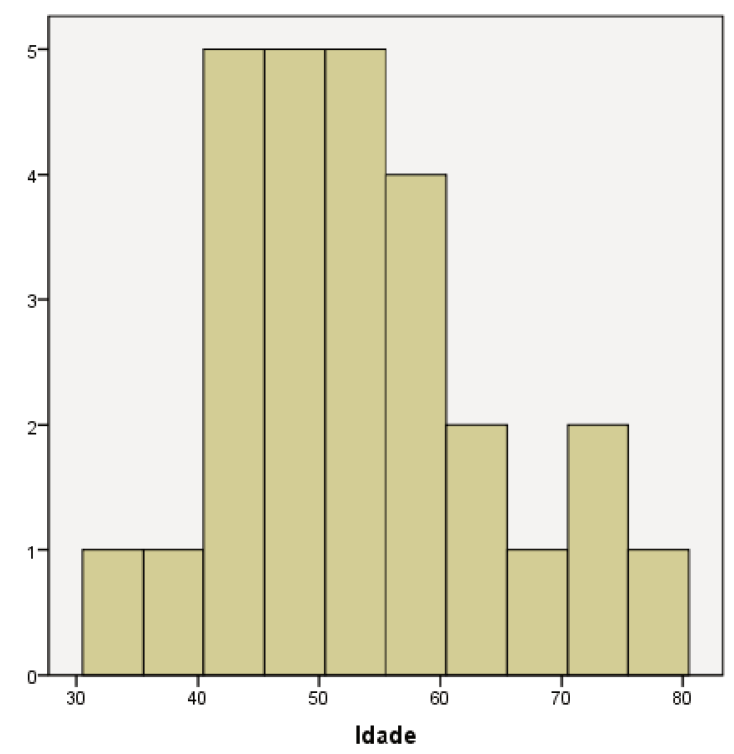

Figura 1 - Distribuição de frequências para as idades dos docentes.

Fonte: Própria

b) Em relação ao gênero, o percentual de professores do sexo masculino é um pouco maior, cerca de $59 \%$ frente aos $41 \%$ do percentual de professores do sexo feminino.

c) O corpo docente do departamento de Matemática da IES possui alta formação acadêmica, sendo que dois terços dos professores possuem o título de doutor. Dos 27 docentes da amostra 20 são doutores, 5 mestres e 2 especialistas. Para as questões relacionadas à titulação docente foi criada uma escala de 1 a 5, sendo a graduação (1), a especialização (2), o mestrado (3), o doutorado (4) e o pós-doutorado (5). 
d) O tempo médio de experiência na educação básica é de 6,0 anos, com erro padrão de $\pm 1,4$ anos. Neste sentido, o corpo docente possui alguma experiência na educação básica.

e) O tempo médio de experiência na educação superior é de 25,3 anos, com um erro padrão de $\pm 2,2$ anos, indicando um corpo docente com bastante experiência na educação superior.

f) O tempo médio de experiência dos docentes do departamento de Matemática na IES é de 16,22 anos, com erro padrão de $\pm 2,6$ anos, indicando, também, um corpo docente com muito tempo na IES, porém inserido em um forte movimento de renovação.

g) $83 \%$ dos docentes que participaram da pesquisa atuam nos cursos de Engenharia.

h) Em relação ao tempo de experiência profissional em atividades não docentes, o corpo docente entrevistado possui pouco tempo, 5,5 anos com erro padrão de $\pm 1,4$ anos.

i) A carga-horária média dos docentes pesquisados foi de 34,2 horas, com erro padrão $\mathrm{de} \pm 2,9$ horas, o que indica que o corpo docente possui elevadíssima carga de trabalho.

j) O percentual médio de horas dedicadas à IES, pelos docentes entrevistados, é de $84,5 \%$, com erro padrão de $\pm 4,1 \%$, o que sugere que o corpo docente tem a IES como a principal fonte de trabalho.

k) A carga-horária média de trabalho, na IES, dos docentes pesquisados foi de 28,5 horas, com erro padrão de $\pm 1,7$ horas, o que indica que o corpo docente tem a IES como principal fonte de trabalho, além de carga-horária próxima ao limite máximo estabelecido pela instituição.

1) Em relação à graduação dos docentes entrevistados, $31 \%$ possuem Licenciatura em Matemática, 24\% Bacharelado em Matemática, 17\% Bacharelado e Licenciatura em Matemática, 14\% Bacharelado em Engenharia, 7\% em Ciências com habilitação em Matemática e 7\% possui Bacharelado em Física.

m) Em relação ao mestrado e ao doutorado, foram criadas, com base na Coordenação de Aperfeiçoamento de Pessoal de Nível Superior (CAPES), cinco áreas, conforme o "Quadro 2" a seguir.

Quadro 2: Áreas da Pós-Graduação

\begin{tabular}{|lc|}
\hline & ÁREAS \\
Educação, Educação Matemática e Ensino de Ciências e Matemática & A1 \\
Física, Ciências, Matemática Pura e Matemática Aplicada & A2 \\
História da Matemática e História da Ciência & A3 \\
Engenharia & A4 \\
Outras & A5 \\
\hline
\end{tabular}

Fonte: Própria. 
Neste sentido, $41,7 \%$ dos docentes pesquisados possuem mestrado na área $\mathrm{A} 1,33,4 \%$ na área $\mathrm{A} 2,8,3 \%$ na área $\mathrm{A} 3,8,3 \%$ na área $\mathrm{A} 4$ 8,3\% na área $\mathrm{A} 5$. Em relação ao doutorado, $35 \%$ indicaram a área $\mathrm{A} 1,25 \%$ a área $\mathrm{A} 4,20 \%$ a área $\mathrm{A} 2,10 \%$ a área $\mathrm{A} 3 \mathrm{e} 10 \%$ a área $\mathrm{A} 5$. Ressalta-se aqui, que mais de $75 \%$ dos docentes entrevistados possuem mestrado em uma das áreas A1 ou A2. O mesmo acontece no doutorado, contudo, com um percentual menor, por volta de $55 \%$.

\section{Análise Cluster, Test t, ANOVA e Correlação}

Nos próximos parágrafos a abordagem metodológica pertinente à análise estatística dos resultados será brevemente descrita. As análises estatísticas foram realizadas com o auxílio do software estatístico SPSS (IBM SPSS Statistics v.19).

Inicialmente procedeu-se a análise descritiva das respostas das questões em variáveis Likert, Ordinal e Métrica, bem como a distribuição de frequências das variáveis categóricas.

Diferenças entre valores referentes às variáveis não categóricas advindas de dois grupos distintos foram investigadas utilizando-se o teste estatístico paramétrico $t$ de Student, a um nível de significância de $5 \%$.

Quando a comparação simultânea de mais de dois grupos era necessária aplicou-se a Análise de Variância - ANOVA, também a um nível de significância de 5\%. Uma vez aplicada a ANOVA e identificada a existência de diferenças entre os grupos, os testes posteriores de Tukey e de Schefe foram utilizados para a determinação dos subgrupos homogêneos.

Análises bivariadas, utilizando o Coeficiente de Correlação de Pearson, testado a um nível de significância de 5\%, foram utilizadas para investigar a existência de correlações entre diversas questões. Tais correlações podem apontar para a existência de uma estrutura latente no conjunto de respostas. A identificação desta estrutura permite estabelecer padrões para o comportamento de conjuntos de questões (ou respondentes) altamente correlacionadas. Para tanto, a informação obtida por meio das questões deve ser analisada em um conjunto, utilizando-se de técnicas estatísticas multivariadas. No caso da análise do questionário, em que grande parte das questões foi formulada em escala de Likert, a técnica multivariada "Análise de Componentes Principais (ACP)" usualmente se destaca, (Pereira, 2004; Gerab, 2014).

Entretanto, a ACP só pode ser aplicada quando o número de respondentes é bastante superior ao número de questões. Este não é o caso em nossa análise, pois o questionário, com 21 questões em escala de Likert, foi respondido por somente 27 professores. Nesta situação a estrutura dos dados pode ser investigada por meio da Análise por Agrupamento Hierárquico AAH, também conhecida por análise de Clusters. O objetivo da AAH é classificar uma 
amostra de entidades (variáveis ou indivíduos) em um pequeno número de grupos mutuamente excludentes, com base nas similaridades entre as entidades (CORRAR et al., 2007).

$\mathrm{Na}$ análise de Clusters, utiliza-se de conceitos essencialmente geométricos para se medir semelhanças (ou dessemelhanças) entre as variáveis. As variáveis (ou os indivíduos) são agrupadas considerando-se as suas distâncias quando colocadas em um espaço n dimensional, tendo como coordenadas os seus valores. Duas amostras são consideradas semelhantes quando a distância geométrica entre elas é pequena. $\mathrm{Na}$ análise por agrupamento as variáveis envolvidas são previamente normalizadas para média zero e variância um, evitando dessa maneira efeitos da métrica (HAIR et. al., 2005).

Argumenta-se que quando o agrupamento se dá por meio das distâncias entre as amostras, medidas no espaço das variáveis, este é chamado de "Agrupamentos por Casos". De forma análoga temos o “Agrupamento por Variáveis”, onde as m variáveis são representadas no espaço $\mathbf{n}$ dimensional das amostras. $\mathrm{O}$ agrupamento das variáveis fornece qualitativamente os grupos das variáveis mais fortemente correlacionadas (Gerab, 1996). Neste trabalho utilizou-se a distância euclidiana quadrática. Na representação desse processo, utiliza-se um diagrama em árvore, chamado de dendograma. No dendograma, um eixo identifica o que foi agrupado, neste caso, as variáveis. O outro eixo corresponde à distância relativa em que foi feito o agrupamento.

Análise por agrupamentos das questões em escala de Likert

Para realizar a análise estatística multivariada das questões em escala de Likert, inicialmente, as questões foram renumeradas de Q1 a Q21.

Contudo, em uma análise mais geral, se percebeu respostas muito positivas para todas as questões propostas. Isto aponta para um padrão mais homogêneo de respostas dos professores. Entretanto, uma análise detalhada, a ser mostrada adiante, mostra uma diferenciação fina entre os docentes. O "Quadro 3" apresenta as médias e os desvios-padrão associados às questões Q1 a Q21. As questões em escala de Likert foram pontuadas de 1 a 5 conforme 1- (discordo totalmente; muito baixa; nunca; muito insatisfeito; péssimo) até 5(concordo totalmente; muito alta, sempre; muito satisfeito, excelente). A questão 5 teve sua escala invertida em função da redação da assertiva. 
Quadro 3: Médias e desvios-padrão associados às questões Q1 a Q21

\begin{tabular}{|c|c|c|c|}
\hline Questão & Assertiva & Média & Desvio-Padrão \\
\hline 1 & $\begin{array}{l}\text { Eu como professor, frequentemente, analiso a minha prática } \\
\text { docente. }\end{array}$ & 4,56 & 0,51 \\
\hline 2 & $\begin{array}{l}\text { Eu analiso e questiono a minha prática docente quando não } \\
\text { consigo prender a atenção dos alunos durante as aulas que } \\
\text { ministro. }\end{array}$ & 4,37 & 0,49 \\
\hline 3 & $\begin{array}{l}\text { Eu analiso e questiono a minha prática docente quando os } \\
\text { alunos questionam a aplicabilidade do conhecimento } \\
\text { matemático ensinado. }\end{array}$ & 4,17 & 0,86 \\
\hline 4 & $\begin{array}{l}\text { Eu analiso e questiono a minha prática docente quando a aula } \\
\text { termina e percebo que os alunos entenderem muito pouco do } \\
\text { que foi ensinado. }\end{array}$ & 4,3 & 0,54 \\
\hline 5 & Eu raramente revisito a minha prática docente. & 4,15 & 0,86 \\
\hline 6 & $\begin{array}{l}\text { Para atender às necessidades e expectativas dos jovens que } \\
\text { chegam, cada vez mais cedo ao Ensino Superior, eu, como } \\
\text { professor, preciso mudar a minha prática de sala de aula. }\end{array}$ & 3,44 & 0,75 \\
\hline 7 & $\begin{array}{l}\text { Ao planejar as aulas, além de conhecer o conteúdo } \\
\text { matemático a ser ministrado, eu, como professor, deveria me } \\
\text { preocupar com a metodologia que será utilizada. }\end{array}$ & 4,30 & 0,72 \\
\hline 8 & $\begin{array}{l}\text { Ao planejar as aulas, além de conhecer o conteúdo } \\
\text { matemático a ser ministrado, eu, como professor, deveria me } \\
\text { preocupar em incluir novos artefatos (softwares, calculadora, } \\
\text { aplicativos,...) para desenvolvê-la. }\end{array}$ & 3,74 & 0,86 \\
\hline 9 & $\begin{array}{l}\text { Ao planejar as aulas, além de conhecer o conteúdo } \\
\text { matemático a ser ministrado, eu, como professor, deveria me } \\
\text { preocupar com a aplicabilidade do que será ensinado. }\end{array}$ & 3,85 & 0,86 \\
\hline 10 & $\begin{array}{l}\text { Ao planejar as aulas, além de conhecer o conteúdo } \\
\text { matemático a ser ministrado, eu, como professor, deveria me } \\
\text { preocupar em pesquisar a aplicabilidade do que será ensinado } \\
\text { no curso de graduação em questão. }\end{array}$ & 3,78 & 0,93 \\
\hline 11 & $\begin{array}{l}\text { Ao planejar as aulas, eu, como professor, deveria me } \\
\text { preocupar em buscar, na literatura da área de Educação } \\
\text { Matemática, estudos sobre o processo de ensino- } \\
\text { aprendizagem do conhecimento matemático a ser ministrado. }\end{array}$ & 3,78 & 0,89 \\
\hline 12 & $\begin{array}{l}\text { Com qual frequência você utiliza a História da Matemática } \\
\text { em suas aulas? }\end{array}$ & 2,48 & 0,70 \\
\hline 13 & $\begin{array}{l}\text { Em que medida você consegue inovar, metodologicamente, } \\
\text { em suas aulas? }\end{array}$ & 3,22 & 0,58 \\
\hline 14 & $\begin{array}{l}\text { Qual é o seu grau de satisfação com a sua prática de sala de } \\
\text { aula? }\end{array}$ & 3,93 & 0,87 \\
\hline 15 & $\begin{array}{l}\text { Qual é a sua predisposição para aprender a lidar com as novas } \\
\text { tecnologias da informação e comunicação (TICs) em sala de } \\
\text { aula? }\end{array}$ & 3,70 & 0,99 \\
\hline 16 & $\begin{array}{l}\text { Qual é a sua predisposição para aplicar as novas tecnologias } \\
\text { da informação e comunicação (TICs) em sala de aula? }\end{array}$ & 3,70 & 0,99 \\
\hline 17 & $\begin{array}{l}\text { Qual é a sua predisposição para aprender a lidar com as novas } \\
\text { abordagens metodológicas em sala de aula? }\end{array}$ & 3,74 & 0,98 \\
\hline 18 & $\begin{array}{l}\text { Qual é a sua predisposição para aplicar as novas abordagens } \\
\text { metodológicas em sala de aula? }\end{array}$ & 3,78 & 0,97 \\
\hline 19 & $\begin{array}{l}\text { Como você avaliaria a qualidade da aprendizagem que ocorre } \\
\text { em suas aulas? }\end{array}$ & 3,74 & 0,53 \\
\hline 20 & $\begin{array}{l}\text { A apreensão do conhecimento matemático, pelo aluno, está } \\
\text { diretamente relacionada à metodologia utilizada pelo } \\
\text { professor em sala de aula? }\end{array}$ & 3,48 & 0,80 \\
\hline 21 & $\begin{array}{l}\text { A apreensão do conhecimento matemático, pelo aluno, está } \\
\text { diretamente relacionada à empatia dele com o professor? }\end{array}$ & 3,63 & 0,74 \\
\hline
\end{tabular}

Fonte: Própria. 
A questão 12, que teve média 2,48, é a de menor média. Com exceção dela e da questão 13 , que teve média 3,22 , todas as demais possuem média elevada.

A avaliação da estrutura interna do padrão de respostas Q1-Q21 foi realizada por intermédio da AAH. Usou-se a matriz de proximidades, o método de Ward, a distância euclidiana quadrática e a normalização dos dados pelas variáveis (questões). O agrupamento por questões apontou a existência de 5 fatores, associados a distintos construtos. O dendograma referente a este agrupamento está apresentado na figura 2.

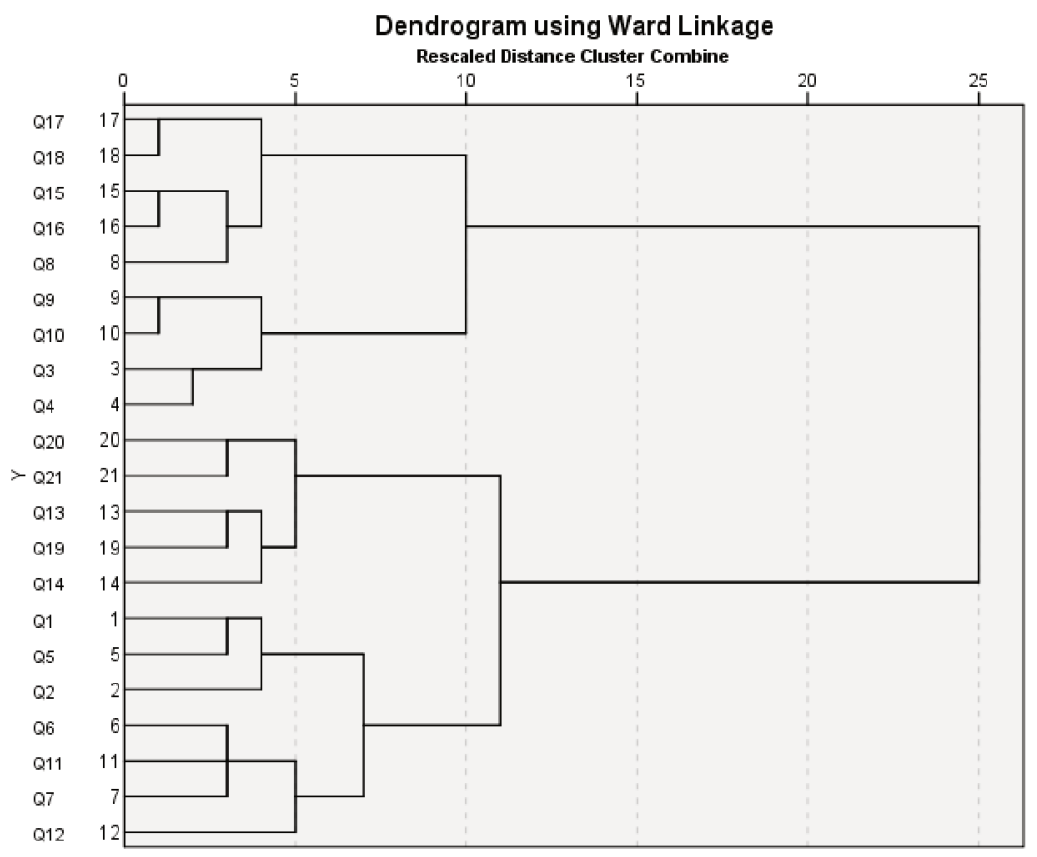

Figura 2 - Dendograma de agrupamento das questões Q1 a Q21.

Fonte: Própria.

Conforme destacado acima, a partir da Análise de Agrupamento, foram criados cinco constructos que foram associados a cinco fatores. A identificação dos agrupamentos e questões a eles associadas possibilitou criar indicadores para estes constructos presentes no agrupamento das questões usando, para isso, a média aritmética das respostas às questões pertencentes a cada grupo. Seguem, conforme indicado no "Quadro 4", os constructos, associados ad hoc aos Fatores, bem como os valores médios de seus indicadores.

Quadro 4: Fatores associados aos padrões de respostas

\begin{tabular}{|l|c|l|c|c|}
\hline Constructo & Fator & Questões & Média & Desvio-Padrão \\
\hline Predisposição para o uso das TIC's & 1 & $\begin{array}{l}\text { Q18, Q17, Q16, } \\
\text { Q15 e Q8 }\end{array}$ & 3,73 & 0,87 \\
\hline $\begin{array}{l}\text { Preocupação com a qualidade dos } \\
\text { processos de ensino e aprendizagem }\end{array}$ & 2 & $\begin{array}{l}\text { Q13, Q19, Q14, } \\
\text { Q20, Q21 }\end{array}$ & 3,60 & 0,54 \\
\hline $\begin{array}{l}\text { Preocupação com a aplicabilidade no } \\
\text { ensino }\end{array}$ & 3 & $\begin{array}{l}\text { Q3, Q9, Q4, e } \\
\text { Q10 }\end{array}$ & 4,02 & 0,70 \\
\hline Frequência da análise da atitude docente & 4 & Q1, Q5 e Q2 & 4,36 & 0,52 \\
\hline $\begin{array}{l}\text { Preocupação com a metodologia e uso da } \\
\text { História e da Educação Matemática }\end{array}$ & 5 & $\begin{array}{l}\text { Q6, Q7, Q11 e } \\
\text { Q12 }\end{array}$ & 3,50 & 0,60 \\
\hline
\end{tabular}

Fonte: Própria. 
Constata-se uma pontuação elevada para todos os fatores. Destacam-se o Fator 4 com a maior pontuação e o Fator 3 com pontuações de 4,36 e 4,02, respectivamente. O Fator 5 mesmo sendo o de menor pontuação ainda foi fortemente considerado pelos professores, atingindo uma pontuação de 3,50. Os desvios-padrão associados aos fatores revelam a pequena variabilidade na opinião dos professores.

Caracterização dos grupos de professores

A primeira caracterização dos professores foi feita a partir do gênero, conforme "Quadro 5", para as variáveis "idade" "formação docente (Nform)", "tempo de experiência na Educação Básica (T_EdBas)", "tempo de experiência na Educação Superior (T_EdSup)", "tempo de experiência na IES (T_IES)", "Porcentagem de atuação no curso de Administração (ADM_\%)", "Porcentagem de atuação no curso de Ciência da Computação (CC_\%)", "Porcentagem de atuação nos cursos de Engenharia (ENG_\%)", "Carga-horária de trabalho na IES (Horas-IES)", "Percentagem de horas dedicadas à IES (IES HORAS \%)", "Carga-horária de trabalho semanal (Horas Totais)" e "tempo de trabalho fora da docência (T_Extra Doc)". $\mathrm{O}$ "teste $\mathrm{t}$ " não indicou distinção entre homens e mulheres para nenhum dos quesitos, a menos de Tempo de experiência na IES (mulheres com menos tempo); Percentagem de atuação na CC (mulheres com percentual maior que dos homens, lembrando que Ciência da Computação é o curso mais jovem da instituição) e tempo extra-atividade docente (as mulheres com menos tempo do que os homens). Estes resultados indicam que não há distinção de gênero no departamento e que as contratações, em décadas recentes, privilegiaram quesitos outros que não o gênero. 
Quadro 5: Estatística dos Grupos

\begin{tabular}{|ll|r|r|r|r|}
\hline & Ngênero & $\mathrm{N}$ & \multicolumn{1}{c|}{ Média } & \multicolumn{1}{c|}{$\begin{array}{c}\text { Desvio- } \\
\text { Padrão }\end{array}$} & Erro Padrão da Média \\
\hline Idade & Mulher & 11 & 49,18 & 7,922 & 2,389 \\
& Homem & 16 & 56,44 & 12,399 & 3,100 \\
\hline Nform & Mulher & 11 & 3,82 & 0,405 & 0,122 \\
& Homem & 16 & 3,56 & 0,964 & 0,241 \\
\hline T_EdBas & Mulher & 11 & 7,18 & 8,670 & 2,614 \\
& Homem & 16 & 5,19 & 6,814 & 1,703 \\
\hline T_EdSup & Mulher & 11 & 21,00 & 8,234 & 2,483 \\
& Homem & 16 & 28,25 & 12,185 & 3,046 \\
\hline T_IES & Mulher & 11 & 10,36 & 5,818 & 1,754 \\
& Homem & 16 & 20,25 & 16,184 & 4,046 \\
\hline ADM_\% & Mulher & 11 & 16,82 & 31,486 & 9,493 \\
& Homem & 16 & 21,26 & 40,308 & 10,077 \\
\hline CC_\% & Mulher & 11 & 23,64 & 41,779 & 12,597 \\
& Homem & 16 & 12,82 & 21,084 & 5,271 \\
\hline ENG_\% & Mulher & 11 & 81,82 & 34,876 & 10,516 \\
& Homem & 16 & 83,38 & 33,400 & 8,350 \\
\hline Horas IES & Mulher & 10 & 25,50 & 5,836 & 1,845 \\
& Homem & 15 & 30,47 & 9,219 & 2,380 \\
\hline IES HORAS \% & Mulher & 10 & 78,30 & 21,955 & 6,943 \\
& Homem & 12 & 89,58 & 15,733 & 4,542 \\
\hline Horas Totais & Mulher & 10 & 32,68 & 18,146 & 5,738 \\
& Homem & 12 & 35,43 & 8,298 & 2,395 \\
\hline T_Extra Doc & Mulher & 11 & 2,91 & 2,982 & 0,899 \\
& Homem & 15 & 7,40 & 8,331 & 2,151 \\
\hline
\end{tabular}

Fonte: Própria.

Ainda em relação às variáveis destacadas no "Quadro 5", detectou-se correlação positiva significativa entre: Idade, tempo no ensino superior e tempo de IES, como era de se esperar. Estas mesmas variáveis são correlacionadas negativamente com a formação acadêmica, indicando que professores mais jovens e mais recentemente contratados possuem uma formação acadêmica mais elevada do que os mais antigos. Isto reflete o empenho institucional em décadas recentes em valorizar a formação acadêmica dos professores contratados, sem detrimento da sua história, representada pelos mais antigos, onde a formação prática, em sala de aula, bastava. Percentual de dedicação ao curso de Engenharia apresenta correlação negativa com o de dedicação na ADM, indicando que as equipes do departamento, que trabalham com estes cursos, são mais isoladas, refletindo a história dos cursos e da criação do departamento de Matemática.

O "teste t" também foi utilizado para comparar as respostas em escala de Likert (Q1 a Q21), separadas por gênero. O teste aplicado indicou que não há distinção entre homens e mulheres para nenhuma das 21 respostas Likert, indicando que a postura do professor não é influenciada por seu gênero.

De maneira análoga à determinação dos Fatores associados às questões quando da aplicação da $\mathrm{AAH}$, esta apontou a existência de distintos constructos latentes no padrão de 
respostas, um segundo agrupamento foi realizado sobre os casos (professores). A identificação de grupos de professores com perfil de respostas semelhantes pode permitir a investigação das características importantes para a separação e distinção dos grupos de docentes. Sendo assim, a AAH foi utilizada para identificar, por meio dos padrões de respostas para as 21 questões em escala de Likert, subgrupos de professores. O dendograma abaixo apresenta o agrupamento dos professores a partir de suas respostas. Os 27 professores foram codificados por meio de números.

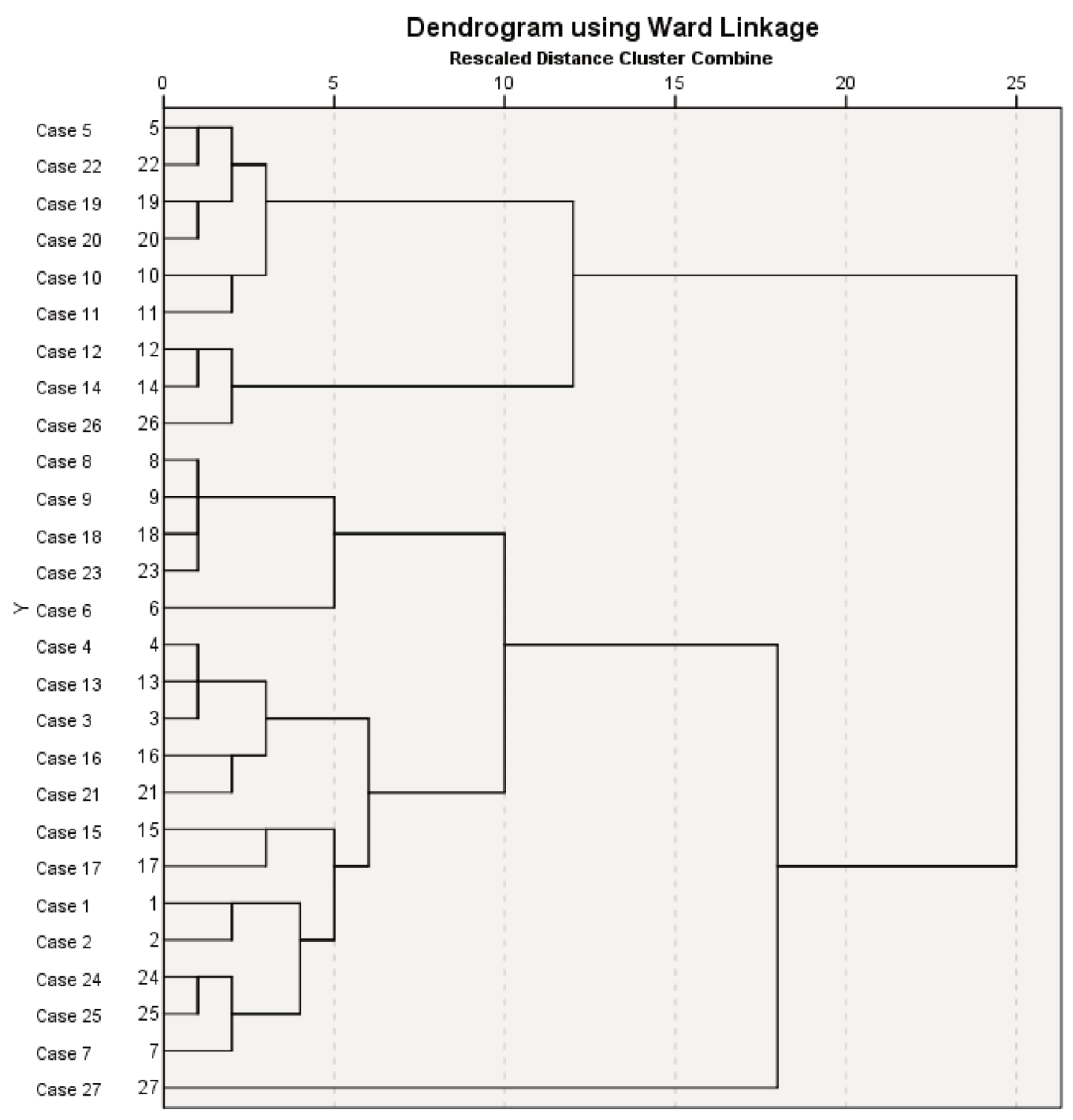

Figura 3 - Dendograma de agrupamento dos professores.

Fonte: Própria.

Esta AAH aponta a existência de 5 grupos. O primeiro, contemplando seis professores $(5,22,19,20,10$ e 11). O segundo é formado por três professores $(12,14$ e 26$)$. O terceiro com cinco professores $(8,9,18,23$ e 6$)$. O maior dos grupos é o quarto, com doze professores $(4,13,3,16,21,15,17,1,2,24,25$, e 7$)$. Um quinto grupo, composto por um único docente (27), se destaca dos demais. Tal fato indica que o padrão de respostas do professor 27 é 
bastante distinto do padrão de respostas de todos os demais professores do departamento de Matemática que participaram da pesquisa.

A ANOVA entre os grupos de professores, considerando somente os quatro primeiros grupos (para tornar a análise estatística matematicamente viável, o grupo cinco, formado por um único docente, foi extraído da análise) e tomando como variáveis cada um dos cinco fatores identificados com constructos presentes no questionário apontou que:

1) O grupo 1 tem score mais elevado do que os demais para o fator 1 Predisposição para novas tecnologias.

2) O grupo 2 tem score mais elevado do que os demais para o fator 2 Preocupação com a qualidade dos processos de ensino e aprendizagem.

3) O grupo 3 tem score pior do que os demais para o fator 3 Preocupação com a aplicabilidade no ensino.

4) O grupo 3 tem score pior do que grupos 1 e 2 para o fator 4 Frequência da análise da atitude docente.

5) O grupo 2 tem score maior do que grupos 3 e 4, enquanto que, o grupo 1 tem score maior do que o grupo 3. Por conseguinte, o grupo 3 tem score menor do que os grupos 1 e 2 para o fator 5 preocupação com a metodologia e uso da História e da Educação Matemática.

Assim, por meio das análises dos fatores e dos grupos de professores, percebeu-se que, embora sutis, os grupos de professores acima possuem, muitas vezes, percepções distintas quanto à relevância de cada uma das dimensões presentes nos processos de ensino e aprendizagem (Fatores) identificadas a partir da análise das questões em escala de Likert. Contudo, uma análise de correlação entre os indicadores dos fatores (constructos) apresenta correlações significativas positivas, a um nível de 0,05 , entre os fatores 1 e $3 ; 2$ e $5 ; 3$ e 4; 3 e 5; 4 e 5. Isto mostra que os fatores, embora tragam informações distintas, não são totalmente independentes.

Constatamos que, utilizando-se de ferramentas quantitativas, não foi possível identificar elementos advindos da caracterização do perfil docente, tais como idade, tempo de IES, formação etc., que caracterizassem, claramente, as razões para composição dos grupos, pois em um mesmo grupo estiveram presentes docentes com características distintas. A análise qualitativa, detalhada abaixo, também se revelou incapaz de tal distinção.

\section{O percurso metodológico para a análise das questões abertas}

A estrutura de análise das questões abertas, respondidas pelos professores, inspirou-se na metodologia da análise de conteúdo proposta por Bardin (2011). 
Um conjunto de técnicas de análise das comunicações visando obter por procedimentos sistemáticos e objetivos de descrição do conteúdo das mensagens indicadores (quantitativos ou não) que permitam a inferência de conhecimentos relativos às condições de produção/recepção (variáveis inferidas) dessas mensagens. (BARDIN, 2011, p. 48)

Ainda segundo Bardin (2011, p. 48), são elementos da análise de conteúdo “[...] todas as iniciativas que, a partir de um conjunto de técnicas parciais, mas complementares, consistam na explicitação e sistematização do conteúdo das mensagens e da expressão deste conteúdo $[\ldots] "$.

A finalidade da análise de conteúdo é realizar deduções lógicas e fundamentadas, relacionadas à origem das mensagens investigadas (o emissor e o seu contexto, ou os efeitos dessas mensagens). (BARDIN, 2011)

O analista possui a sua disposição (ou cria) todo um jogo de operações analíticas, mais ou menos adaptadas à natureza do material e à questão que procura resolver. Pode utilizar uma ou várias operações, em complementaridade, de modo a enriquecer os resultados, ou aumentar a sua validade, aspirando assim a uma interpretação final fundamentada. Qualquer análise objetiva procura fundamentar impressões e juízos intuitivos, por meio de operações conducentes a resultados de confiança. (BARDIN, 2011, p. 48)

Neste sentido, o método da análise de conteúdo consiste na organização da análise, na codificação, na categorização e na inferência. Em nosso estudo, procuramos seguir a estrutura da organização proposta por Bardin (2011), todavia, com certo grau de liberdade.

Análise das questões abertas

A análise de conteúdo foi aplicada nas questões abertas $(22,30,33,39,40,44,47$ e 48) do questionário respondido pelos docentes. As respostas dadas pelos professores foram organizadas, segundo os grupos (G1, G2, G3 e G4) construídos após a análise estatística das questões quantitativas.

Questão 22. Cite, se possível, outros momentos em que você analisa e questiona a sua prática docente.

Ao analisarmos as respostas dadas à Questão 22, destacamos que os outros momentos em que o grupo G1 analisa e questiona a sua prática estão associados, com maior frequência, às palavras-chave "planejamento" (33\%) e "cronograma" (33\%). Já no grupo G2 estes outros momentos estão associados, preponderantemente, à palavra-chave "aluno" (100\%). Ao grupo G3, os outros momentos, estão associados, igualmente, às palavras-chave "planejamento" (25\%), "avaliação" (25\%), "aluno" (25\%) e "coordenador" (25\%). Em relação ao grupo G4, destacam-se as palavras-chave "aluno" (50\%) e "planejamento" (25\%).

Na análise da questão 22 as palavras-chave que mais apareceram foram: "aluno" (37\%); "planejamento" (26\%); "avaliação" (11\%); e "cronograma" (11\%). 
Em relação à palavra-chave "planejamento", 40\% das respostas foram dadas pelo grupo G1 e outros $40 \%$ pelo grupo G4; para a palavra-chave "aluno", 57\% das respostas foram dadas pelo grupo G4; para a palavra-chave "cronograma", 100\% das respostas foram dadas pelo grupo G1; por fim, para a palavra-chave "avaliação", 50\% das respostas foram dadas pelos professores do Grupo G3 e os outros 50\% foram dados pelo grupo G4.

Questão 30. Quais são os artefatos (softwares, calculadora, aplicativos,...) utilizados no desenvolvimento de suas aulas?

Ao analisarmos as respostas dadas à Questão 30, destacamos que o grupo G1 utiliza para o desenvolvimento de suas aulas, principalmente, os artefatos - Softwares (50\%), Calculadoras (25\%) e Internet (25\%). O grupo G2 utiliza os artefatos - Calculadoras (50\%); Power Point (25\%) e Excel (25\%). Já o grupo G3 utiliza os artefatos - Softwares (50\%), Calculadoras (25\%) e Power Point (25\%). Por fim, o grupo G4 utiliza para o desenvolvimento de suas aulas, principalmente, os artefatos - Softwares (46\%); Calculadoras (25\%); Power Point (13\%) e Internet (9\%).

Na análise da questão 30 as palavras-chave que mais apareceram foram: "Softwares" (43\%), "Calculadoras" (27\%), "Power Point" (14\%) e "Internet" (9\%). Em relação aos softwares citados, destacam-se, o Matlab (26\%) e o Winplot (21\%).

Em relação à palavra-chave "Softwares", 58\% das respostas foram dadas pelos professores do grupo G4, 21\% das respostas foram dadas pelo grupo G1 e os demais $21 \%$ foram respondidos pelo grupo G3; para a palavra-chave "Calculadoras", 50\% das respostas foram dadas pelos professores do grupo G4 e os $50 \%$ restantes foram distribuídos, igualmente, pelos grupos G1, G2 e G3; para a palavra-chave "Power Point", 50\% das respostas foram dadas pelos professores do grupo $\mathrm{G} 4,33 \%$ pelos professores do grupo G3 e os restantes $17 \%$ pelos professores do grupo G2; por fim, para a palavra-chave "Internet, $50 \%$ das respostas foram dadas pelos professores do grupo G4 e os demais $50 \%$ pelos professores do grupo G1.

Questão 33. Relate, se possível, uma experiência de sala de aula (sua ou de outro professor) de sucesso ou fracasso.

Ao analisarmos as respostas dadas à Questão 33 (experiência de sucesso), destacamos que o grupo G1 associa a experiência de sucesso ao uso - da tecnologia (57\%); do mapa conceitual (14\%); da estratégia de trabalho em grupo (14\%); e de material impresso (para todos os alunos) mesclando teoria e exercícios (14\%). O grupo G2 associa ao uso - da estratégia de trabalho em grupo (50\%); e de atividades que privilegiam o pensamento intuitivo (50\%). O grupo G3 associa ao uso - da História da Matemática (25\%); da estratégia de trabalho em grupo (25\%); de situações-problema (25\%); e $25 \%$ dos professores do grupo G3 consideram que há experiência de sucesso quando o aluno é aprovado. Por fim, o grupo 
G4 associa ao uso - da tecnologia (50\%); da História da Matemática (25\%); e de situaçõesproblema (25\%).

Na análise da questão 33 as palavras-chave que mais apareceram associadas ao SUCESSO foram: "Tecnologia" (35\%), "Trabalho em grupo" (18\%), "História da Matemática" (12\%) e "Situação-problema" (12\%).

Em relação à palavra-chave "Tecnologia", 67\% das respostas foram dadas pelos professores do grupo G1 e $33 \%$ pelos professores do grupo G4; para a palavra-chave "Trabalho em grupo", 33\% das respostas foram dadas pelos professores do grupo G1, 33\% pelos professores do grupo G2 e 33\% pelos professores do grupo G3; para a palavra-chave "História da Matemática", 50\% das respostas foram dadas pelos professores do grupo G3 e os $50 \%$ restantes pelos professores do grupo G4; por fim, para a palavra-chave "Situaçãoproblema", $50 \%$ das respostas foram dadas pelos professores do grupo G3 e os $50 \%$ restantes pelos professores do grupo G4.

Ao analisarmos as respostas dadas à Questão 33 (experiência de fracasso), destacamos que o grupo G1 associa a experiência de fracasso, principalmente, à falta de sinergia com o professor com quem divide a disciplina (100\%). O grupo G2 associa ao uso excessivo de algoritmo em EDO (Equações Diferenciais Ordinárias) (100\%). O grupo G3 associa uma experiência de sala de aula, de fracasso, principalmente, quando há reprovação do aluno (100\%). Por fim, o grupo G4 associa ao uso de tecnologia (33\%); ao trabalhar as demonstrações em sala de aula (33\%); e à falta de sinergia com o professor com quem divide a disciplina (33\%).

Na análise da questão 33 a palavra-chave que mais apareceu associada ao FRACASSO foi: "falta de sinergia com o professor com quem divide a disciplina" (33\%). As demais palavras-chave "tecnologia", "demonstrações", "reprovação do aluno" e "excesso de algoritmo em EDO” tiveram a mesma frequência (17\%).

Em relação à palavra-chave "falta de sinergia com o professor com quem divide a disciplina", $50 \%$ das respostas foram dadas pelos professores do grupo G1 e os $50 \%$ restantes pelos professores do grupo G4.

Questão 39. Qual é a sua principal preocupação ao ministrar as suas aulas?

Ao analisarmos as respostas dadas à Questão 39, destacamos que o grupo G1, ao ministrar as suas aulas, preocupa-se tanto com o conteúdo quanto com o aluno. Já os demais grupos G2, G3 e G4 preocupam-se mais com o aluno do que com o conteúdo.

Na análise da questão 39 as palavras-chave que apareceram foram "conteúdo" $(27 \%)$ e "aluno" (73\%).

Em relação à palavra-chave "conteúdo", 50\% das respostas foram dadas pelo grupo G1, 38\% foram dadas pelo grupo G4 e $12 \%$ pelo grupo G2. Em relação à palavra-chave 
"aluno", 50\% das respostas foram dadas pelo grupo G4, 23\% pelo grupo G3, $18 \%$ pelo G1 e $9 \%$ pelo grupo $\mathrm{G} 2$.

Questão 40. O ensino que você pratica em sala de aula privilegia a construção do conhecimento matemático pelo aluno? Em caso negativo, o que ele privilegia?

Ao analisarmos as respostas dadas à Questão 40, destacamos que os quatro grupos consideram que o ensino, praticado em suas aulas, privilegia a construção do conhecimento matemático pelo aluno, contudo, nos grupos G1 e G3 há um equilíbrio entre o sim e o não. Para 57\% dos docentes, que responderam não à questão 40, o ensino praticado em suas aulas privilegia a transmissão de conhecimento. Para $29 \%$ dos docentes, que responderam não à questão 40, o ensino praticado em suas aulas privilegia o cumprimento do cronograma. Para $14 \%$, o ensino privilegia a utilização de técnicas.

Questão 44. Quais são os instrumentos que você utiliza para avaliar a qualidade da aprendizagem que ocorre em suas aulas?

Ao analisarmos as respostas dadas à Questão 44, destacamos que o grupo G1 utiliza, como instrumento para avaliar a qualidade da aprendizagem que ocorre em suas aulas "questionamentos aos alunos" (29\%), “provas" (29\%), “atividades" (21\%) e "exercícios durante as aulas" (21\%). O grupo G2 também utiliza, predominantemente, os mesmos instrumentos, porém privilegiam mais as "provas" (40\%). O instrumento "questionamentos aos alunos" (20\%) e "atividades" (20\%) tiveram o mesmo percentual. No caso do grupo G3, eles privilegiam "provas" (38\%), "questionamentos aos alunos" (25\%), "exercícios durante as aulas" (25\%) e "atividades" (13\%). O grupo G4 também privilegia, predominantemente, os mesmos instrumentos, contudo, "provas" (37\%) é o principal instrumento, seguido pelas "atividades" (21\%), "questionamentos aos alunos" (16\%) e "exercícios durante as aulas" $(16 \%)$.

As palavras-chave "provas" e "questionamentos aos alunos" foram as que mais apareceram em, respectivamente, $35 \%$ e $22 \%$ das respostas dadas pelos docentes.

Questão 47. Cite, se possível, outros fatores que contribuem para a apreensão do conhecimento matemático pelo aluno.

Ao analisarmos as respostas dadas à Questão 47, destacamos que para o grupo G1 outros fatores que contribuem para a apreensão do conhecimento matemático pelo aluno são a "dedicação" (44\%), a "motivação" (22\%), a "utilidade do conhecimento" (11\%), a "metodologia" (11\%) e a "empatia" (11\%). Para o grupo G2, os outros fatores são a "dedicação" (25\%), a "utilidade do conhecimento" (25\%), a "metodologia" (25\%) e a "empatia" (25\%). O grupo G3 destaca os fatores "dedicação" (33\%), "maturidade" (25\%), "motivação" (8\%), "metodologia" (8\%), "empatia" (8\%), "ambiente" (8\%) e "apoio" (8\%). Por fim, o grupo G4 indica os fatores "dedicação" (42\%), "utilidade do conhecimento" (17\%), 
"base matemática" (17\%), "maturidade" (8\%), "metodologia" (8\%) e "paciência docente" $(8 \%)$.

Na análise da questão 47 as palavras-chave que mais apareceram foram "dedicação" com $38 \%$ das respostas, "utilidade do conhecimento" $11 \%$, "maturidade" $11 \%$, "metodologia" 11\%, "motivação" $8 \%$ e "empatia" $8 \%$. A palavra-chave "base matemática" apareceu apenas em 5\% das respostas dadas pelos docentes.

Em relação à palavra-chave "dedicação", há um equilíbrio, no percentual de respostas, entre os grupos G1 (29\%), G3 (29\%) e G4 (33\%). Para a palavra-chave "utilidade do conhecimento" $50 \%$ das respostas foram dadas pelo grupo G4, $25 \%$ pelo grupo G2 e $25 \%$ pelo grupo G1. A palavra-chave "maturidade" foi, predominantemente, destacada pelo grupo G3 (75\%), bem como, "motivação" foi destacada pelo grupo G1 (67\%). A palavra-chave "empatia" foi igualmente citada pelos grupos G1, G2, e G3 com 33\%. Por fim, a palavrachave "metodologia" foi citada, igualmente, por todos os quatro grupos.

Questão 48. Cite, se possível, outros fatores que contribuem para o desinteresse, a dispersão (quando ocorre) dos alunos durante as aulas ministradas por você.

Ao analisarmos as respostas dadas à Questão 48, destacamos que para o grupo G1 outros fatores que contribuem para o desinteresse, a dispersão (quando ocorre) dos alunos durante as aulas são: "metodologia" (40\%), "dificuldade com a Matemática Básica" (20\%), "interação com o celular" (20\%) e "falta da cultura do estudo" (20\%). Para o grupo G2, os outros fatores são "interação com o celular" (50\%), "metodologia” (50\%). O grupo G3 destaca os fatores "dificuldade com a Matemática Básica" (22\%), "interação com o celular" $(22 \%)$, "falta da cultura do estudo" (11\%), "imaturidade" (11\%), "falta de comprometimento" (11\%), "fatores físicos" (11\%) e "fatores emocionais" (11\%). Por fim, o grupo G4 indica os fatores "falta de comprometimento" (32\%), "dificuldade com a Matemática Básica" (20\%), "imaturidade" (16\%), "metodologia" $(12 \%)$, "interação com o celular", "falta da cultura do estudo", "conversa", "espaço físico" e "empatia com o curso", todos com o mesmo percentual de $4 \%$.

Na análise da questão 48 as palavras-chave que mais apareceram foram "falta de comprometimento" (22\%), "dificuldade com a Matemática Básica" (19,5\%), "metodologia" (15\%), "imaturidade" (12\%) e "interação com o celular" (12\%).

Em relação à palavra-chave "falta de comprometimento" $89 \%$ foram indicadas pelos professores do grupo G4. Para a palavra-chave "dificuldade com a Matemática Básica" 63\% foram apresentadas pelos professores do grupo G4. Já para a palavra-chave "metodologia" $50 \%$ das indicações foram feitas pelos professores do grupo 4. Para a palavra-chave "imaturidade", novamente o grupo G4 se destacou indicando-a em $80 \%$ das respostas. A palavra-chave "interação com o celular" foi mais indicada, com $40 \%$, pelo grupo G3, 
enquanto que "falta da cultura do estudo" foi distribuída, igualmente nos grupos G1, G3 e G4, como 33\%. Acreditava-se que a palavra-chave "interação com o celular" tivesse um percentual de indicação maior, contudo, isso não ocorreu.

Considerações acerca da análise das questões abertas

As questões abertas não eram obrigatórias, mas, mesmo assim, o percentual de professores que não respondeu foi baixo, aproximadamente $26 \%$. As questões abertas tinham a intenção de complementar as questões em escala de Likert. Conforme destacado, anteriormente, agrupamos as palavras-chave tomando como referência os grupos construídos na análise estatística quantitativa, pois esperávamos encontrar algum padrão de respostas, mesmo nas questões abertas, contudo, isto não ocorreu e, por isso, a nossa análise, apesar de separada pelos grupos, refletiu a opinião do coletivo de professores, independentemente, dos grupos, aos quais, eles foram agrupados. Algo que nos inquietou, ao longo da análise realizada envolvendo o questionário aplicado aos docentes, foi, justamente, a dificuldade de estabelecer, pelo menos uma característica, que justificasse a separação dos professores nos grupos G1, G2, G3 e G4. Nem a análise das questões quantitativas, muito menos, das questões qualitativas foi capaz de estabelecer, pelo menos uma característica. Tal fato, como já destacado anteriormente, indica que há homogeneidade no trabalho docente realizado pelos professores do departamento de Matemática, ou seja, o professor se adapta e, rapidamente, se incorpora tanto à política do departamento quanto à política institucional, o que, do nosso ponto de vista, indica algo muito positivo para a própria instituição estudada.

Contudo, algumas considerações precisam ser feitas sobre as questões abertas. Neste sentido, destaca-se, positivamente, na questão 22, o fato de que o aluno é o principal responsável pela análise e questionamento da prática pelo professor. Tal fato pode ser comprovado pela questão 39, que tratava, justamente, de verificar qual era a principal preocupação, dos professores, ao ministrarem suas aulas.

Em relação à experiência de sala de aula associada ao sucesso, o uso da Tecnologia apresentou o maior percentual, contudo, aquém do que se espera. No que diz respeito à experiência de sala de aula associada ao fracasso, destaca-se o baixo percentual de experiências relatadas, qual seja $22 \%$ do total de professores que participaram da pesquisa.

Já na questão 40, que perguntava aos professores se o ensino praticado em suas aulas privilegiava a construção do conhecimento matemático pelo aluno, 73\% responderam que sim, ou seja, que as suas aulas privilegiavam a construção do conhecimento matemático pelo aluno, contudo, consideramos que está questão precisa ser investigada com mais profundidade, uma vez que não foi perguntado ao professor o que ele entendia por construção do conhecimento. 
Em relação à questão 47, que tratava sobre os outros fatores que contribuem para a apreensão do conhecimento matemático pelo aluno, os professores indicaram que a dedicação, a motivação e a maturidade dos alunos, são responsáveis por, aproximadamente, $57 \%$ da apreensão do conhecimento matemático.

Por fim, na questão 48, que perguntava sobre os outros fatores que contribuem para o desinteresse, a dispersão dos alunos durante as aulas das disciplinas de Matemática, a falta de comprometimento, a imaturidade, a interação com o celular e a falta de cultura do estudo representam um percentual de, aproximadamente, 54\%. Já a dificuldade com a Matemática Básica apresentou um percentual inferior a $20 \%$, o que, possivelmente, indica que os alunos dos cursos de Engenharia conseguem, ao longo dos primeiros semestres, minimizar, quando existe, a defasagem dos conteúdos matemáticos da Educação Básica.

\section{Considerações finais}

Os resultados alcançados após as análises quantitativa e qualitativa apontam para uma opinião relativamente homogênea sobre os cinco constructos identificados. Opiniões estas consistentes com a cultura institucional vigente na IES. Tal fato aponta a presença de uma forte influência da história pedagógica da IES sobre o conjunto de seus docentes. Este fato apresenta-se em concordância com relatos tomados de professores mais antigos do departamento de Matemática, quando, sob a perspectiva de cada docente, documentou-se a trajetória profissional de cada um deles no ensino superior e, particularmente, na IES estudada. Este trabalho foi realizado dentro de um projeto intitulado "Retraços do ensino de Matemática nos cursos de Engenharia no ABC Paulista: uma história não contada" (PARRA; GODOY, 2014).

As pequenas diferenças existentes entre os grupos de professores parecem estar mais associadas às concepções pedagógicas individuais de cada docente, sem com isso, indicar um grupo característico de professores.

Constata-se uma forte adesão dos docentes à cultura organizacional da IES. Portanto, qualquer indução a uma mudança de abordagens e de procedimentos pedagógicos na IES deve atentar-se, primeiramente, às políticas institucionais, e não somente às atitudes individuais dos docentes, uma vez que a visão corporativa na IES estudada e suas tradições parecem sobrepor-se às visões individuais.

Ainda sobre esta questão, é importante destacar que, após as análises feitas, existe a percepção, por parte dos responsáveis pela elaboração, aplicação e análise dos resultados da pesquisa, que a amostra coletada dos professores sujeitos da nossa investigação, cada vez mais participam das decisões, bem como, fazem críticas e sugestões ao coletivo de professores, o que pode indicar que este corpo de professores faz parte de um grande grupo 
colaborativo em que - as trocas de experiências de fracasso e sucesso são feitas; a dúvida é explicitada sem o receio de ser criticado por não saber algo; e os professores com mais tempo e experiência na IES ou na disciplina são consultados para esclarecer as dúvidas e para trocar experiências.

Parafraseando um dos professores mais experientes da IES, em seu depoimento no projeto de Parra e Godoy (2014), o espaço coletivo da academia é um dos ambientes mais ricos para se desenvolver intelectualmente, e talvez seja por isso, tão difícil, a um professor universitário, se aposentar, pois em qual outro lugar, ele se sentirá tão vivo? Para eles, o espaço de sala de aula, em contato com os jovens é sinal de vida, de muita vida, mesmo quando eles, os alunos, querem, ao mesmo tempo, prestar atenção no que o professor ensina, na conversa ao lado, nas redes sociais....

$\mathrm{O}$ estudo em questão, embora tenha sido aplicado a um pequeno o grupo de professores $(n=27)$ se mostrou, do nosso ponto de vista, uma boa ferramenta de análise a respeito da percepção docente acerca do olhar atento para os estudantes ingressantes nos cursos universitários iniciais de Matemática, requeridos para estudos nas áreas de Engenharia, Ciências e Matemática.

A predisposição para o uso das TIC's, a preocupação com a qualidade dos processos de ensino e aprendizagem, com a aplicabilidade do ensino, com a metodologia e o uso da História e da Educação Matemática e a frequência da análise da atitude docente são constructos que, num primeiro momento, podem ser utilizados para mensurar a inércia docente (do corpo docente) a respeito do acolhimento aos discentes (estudantes universitários).

Num segundo momento, esses constructos podem contribuir para a proposição de iniciativas (individuais, departamentais e institucionais) que tenham como objetivo elaborar, planejar e aplicar ações (projetos, programas) para minimizar o impacto causado pela transição da Educação Básica para a Educação Superior.

Neste sentido, concordamos com Almeida (2016) que, em seu estudo sobre a evasão nos cursos de Engenharia e a sua relação com a Matemática, percebeu a existência de avanços nas discussões relacionadas à Educação Matemática no Ensino Superior, contudo, o aumento dos trabalhos, bem como das pesquisas, associado ao ensino de Matemática nos cursos superiores, tem indicado que apenas conhecer bem o conteúdo a ser ensinado não é suficiente.

[...] é necessário incorporar teorias associadas à educação; apresentar contextos significativos aos alunos; usar, sobremaneira, as ferramentas computacionais para construir o conhecimento matemático e, por fim, acolher os alunos, tratando de oportunizar ambientes em que eles possam preencher as lacunas conceituais advindas de uma formação educacional básica deficiente. (ALMEIDA, 2016, p. 84) 
Sendo assim, ao pensarmos em aulas mais operatórias, que potencializam as relações existentes entre o mundo e a disciplina, entre a teoria e a prática, conjecturamos que os cursos universitários iniciais de Matemática contribuirão para melhorar a transição das matemáticas escolar e acadêmica, bem como melhorar a comunicação entre os docentes dos dois níveis educacionais.

Há outros fatores (social, cultural, econômico, psicológico, entre outros) que interferem diretamente no processo de adaptação acadêmica dos estudantes ingressantes, todavia, docentes e IES deverão assumir o compromisso de contribuírem para que os estudantes tenham melhores vivências acadêmicas nas dimensões pessoal e de realização acadêmica que, por consequência, conforme estudo desenvolvido por Cunha e Carrilho (2005), acarretarão melhor rendimento escolar, logo menos insucesso, abandono e evasão escolar.

A respeito da evasão, ou melhor, da redução dela e da retenção no ensino superior tem sido um tema recorrente e fundamental para o aprimoramento do sistema educacional. Distintos autores se debruçam sobre o tema no Brasil e no mundo. Um estudo sobre a relação entre o insucesso acadêmico e a evasão nos cursos de engenharia da Universidade do Minho (Vasconcelos et al, 2009) mostrou existir uma relação complexa entre estes fatores, pois embora os cursos de engenharia apresentem taxas de reprovação superiores às taxas médias da Universidade, sua taxa de desistência situa-se abaixo da taxa de desistência média da Universidade. Entretanto, as maiores taxas de evasão dos cursos de engenharia situam-se no primeiro ano do ensino superior, associando-se às possíveis dificuldades dos estudantes em sua transição para o ensino superior, notadamente à falta de correspondência entre as expectativas dos estudantes antes do início do curso e a realidade com que se confrontam posteriormente. Vários trabalhos buscam mensurar e identificar as causas de evasão. Bardagi e Hutz (2009) em uma pesquisa qualitativa com estudantes evadidos concluem que "a decisão de evadir foi majoritariamente impulsiva, causada por uma insatisfação de longo prazo e não relacionada à novas escolhas de carreira." Já Silva filho e colaboradores (Silva Filho, 2007) apontam que a evasão é um problema internacional capaz de afetar o próprio resultado dos sistemas educacionais. Em seus trabalhos, calculando tanto a taxa de Evasão Anual Média como a Evasão Total, os autores apontam que a taxa de evasão no primeiro ano do curso é duas à três vezes superior às dos anos subsequentes. Avaliando diversas áreas do conhecimento estes autores verificaram que a evasão nos cursos superiores do Brasil não difere muito das médias internacionais, porém variam bastante por curso, região e dependência administrativa (pública ou privada). 


\section{Referências}

ALMEIDA, E. de; A evasão nos cursos de Engenharia e a sua relação com a Matemática: uma análise a partir do COBENGE. Dissertação de mestrado em Ensino de Ciências e Matemática - Universidade Cruzeiro do Sul, São Paulo, 2016.

BARDIN, L. Análise de Conteúdo. Edição revista e ampliada. Tradução de Luís Antero Reto e Augusto Pinheiro. São Paulo: Edições 70, 2011.

BARDAGI, M. P.; HUTZ, C. S Não havia outra saída: percepções de alunos evadidos sobre o abandono do curso superior. PsicoUSF, v. 14, n. 1, p. 95-105, 2009

BASEIO, M. A. F.; GARCIA, R. E, Didática no Ensino Superior. São Paulo: Pós-Graduação da Faculdade Radial, 2010.

CORRAR, L. J.; PAULO, E.; DIAS FILHO, J. M. Análise Multivariada: para cursos de Administração Ciências Contábeis e Economia. São Paulo: Atlas, 2007.

CUNHA, S. M.; CARRILHO, D. M. O Processo de adaptação ao Ensino Superior e o rendimento acadêmico: adaptação e rendimento acadêmico. Psicologia Escolar e Educacional, v. 9, n. 2, p. 215-224, 2005.

DIAS, M. A.; MATEUS, P. Estudo comparado da transição entre o Ensino Médio e o Ensino Superior: análise das organizações didático-matemáticas dos documentos orientadores do Brasil e de Moçambique. REVEMAT, v. 10, n. 2, p. 139-154, 2015.

GERAB, F. Técnicas analíticas nucleares aplicadas a medida em larga escala de aerossóis atmosféricos na região amazônica. Tese de Doutorado. Universidade de São Paulo. Instituto de Física, 1996.

FERREIRA GERAB, I. F.; BATISTA, S. H.; SONZOGNO, M. C.; YAMASHIRO, C. G.; GERAB, F. MORENO, L. R. Avaliação da disciplina Formação Didático-Pedagógica em Saúde: a ótica dos pós-graduandos. RBPG. Revista Brasileira de Pós-Graduação, v. 11, n. 24, p. 533-552, 2014.

HAIR, J. F. Jr.; ANDERSON, R.E.; TATHAM, R.L.; BLACK, W.C. Análise multivariada de dados. Porto Alegre: Bookman, 2005.

PARRA, J. B., GODOY, E. V. Retraços do ensino de Matemática nos cursos de Engenharia no ABC Paulista: uma história não contada. Relatório Final (Iniciação Científica). Centro Universitário da FEI, São Bernardo do Campo, 2014. Disponível em https://interage.fei.org.br/secureserver/pipex/ExibirArquivo.aspx?id=1169.

Último acesso em: 12 ago. 2018.

PALIS, G. de L. R. A transição do Ensino Médio para o Ensino Superior. In: X ENCONTRO NACIONAL DE EDUCAÇÃ̃ MATEMÁTICA. Salvador, BA. Anais, Salvador, 2010. Disponível em: http://www.lematec.net.br/CDS/ENEM10/artigos/PA/Palestra4.pdf. Último acesso em: 12 ago. 2018.

PEREIRA, J. C. R. Análise de Dados Qualitativos: estratégias metodológicas para ciência da saúde, humanas e sociais. $3^{\mathrm{a}}$ ed. São Paulo: EDUSP/FAPESP, 2004.

SILVA FILHO, R. L. L.; MOTEJUNAS, P. R.; HIPOLITO, O.; LOBO, M. B. de C. M. A evasão no ensino superior brasileiro. Cadernos de Pesquisa, v. 37, n. 132, p. 641-659, 2007. 
VASCONCELOS, R.; ALMEIDA, L. S.; MONTEIRO, S. O insucesso e abandono acadêmico na universidade: Uma análise sobre os cursos de engenharia. In: INTERNATIONAL CONFERENCE ON ENGINEERING AND COMPUTER EDUCATION (ICECE 2009), 6, Buenos Aires, Argentina, 2009 - "International Conference on Engineering and Computer Education". Proceedings, Buenos Aires: ICECE, cop. 2009. p. 457-461.

TOZZI, M.; OTA, J. Vertedouro em degraus. Revista da Vinci, Curitiba, v.1, n.1, p. 9-28, 2004.

\section{SOBRE OS AUTORES}

ELENILTON VIEIRA GODOY. Possui graduação em Bacharelado em Matemática pela Pontifícia Universidade Católica de São Paulo (1998), graduação em Licenciatura Plena em Matemática pelo Centro Universitário Sant'Anna (1999), mestrado em Educação Matemática pela Pontifícia Universidade Católica de São Paulo (2002), doutorado em Educação pela Universidade de São Paulo (2011) e pós-doutorado em Educação junto à Faculdade de Educação da Universidade de São Paulo (2018). Atualmente é professor do departamento de Matemática, do Programa de Pós-Graduação em Educação em Ciências e em Matemática e do Programa de Pós-Graduação em Educação da Universidade Federal do Paraná (UFPR). Tem experiência na área de Ensino de Matemática desenvolvendo estudos e pesquisas associadas aos aspectos teóricos do currículo da Matemática escolar e à transição do Ensino Médio para o Ensino Superior. ORCID iD: 0000-0001-8081-5813.

FABIO GERAB. Possui graduação em Física pela Universidade de São Paulo (1985), mestrado em Física Nuclear pela Universidade de São Paulo (1989), doutorado em Física Aplicada pela Universidade de São Paulo e parcialmente desenvolvido na Universidade de Lund, Suécia (1996) e pós-doutorado em HR-ICP-MS junto ao Instituto de Pesquisas Energéticas e Nucleares (1997). Mais de dez anos de experiência em desenvolvimento de produto na indústria automotiva. Professor Titular e chefe do Departamento de Matemática do Centro Universitário FEI. Líder do Grupo de Educação Matemática e Matemática no Ensino Superior - GEMMES, cadastrado no Diretório de Grupos de Pesquisa do CNPq. Tem experiência nas áreas de Educação, Estatística, Física Nuclear, Física Aplicada à Estudos Ambientais, Engenharia Automotiva, Acústica e Vibração, Ergonomia Automotiva e Gestão da Qualidade. ORCID iD: 0000-0001-7869-8048

Recebido: 12 de outubro de 2017.

Revisado: 12 de agosto de 2018.

Aceito: 24 de agosto de 2018. 